\title{
THE CORRELATION OF THE HUMAN DEVELOPMENT INDEX (HDI) TOWARDS ECONOMIC GROWTH (GDP PER CAPITA) IN 10 ASEAN MEMBER COUNTRIES
}

\author{
Elistia $^{1)}$, Barlia Annis Syahzuni ${ }^{1)}$ \\ ${ }^{1)}$ Universitas Esa Unggul, Jakarta, Indonesia \\ Corresponding Author: elistia@esaunggul.ac.id
}

\begin{abstract}
Economic growth is an important factor in the economic development of a country. There is a number of factors that can increase economic growth namely human development. The level of human development in a country array in the value of the Human Development Index (HDI). The growth rate of a country appears in the value of the Gross Domestic Product (GDP) per Capita. The influence of human power resources is shown in the value of HDI which is able to influence the level of economic growth in the value of its GDP. This study will examine the effect of HDI on economic growth in 10 (ten) ASEAN member countries during the period 2010-2016, namely Indonesia, Singapore, Malaysia, Thailand, Brunei Darussalam, Philippines, Laos, Vietnam, Myanmar, and Cambodia against its economic growth in its GDP per capita. Several literature studies such Ciobanu Oana (2015), Swaha Shome et.al (2010), Mihut Loana Sorina (2013), show that there are a relationship and an influence of Human Development Index's value on Gross Domestic Product (GDP) per capita. The result of this research indicates that each country has a strong and significant correlation between HDI and GDP. It is concluded that the level of HDI can affect the GDP per capita. Economic growth makes it possible to reach a high level of human development, on the one hand, increasing levels of human development leading to increase opportunities for economic growth. The causal relationship between economic growth and human development becomes a mutually influential relationship. So it is clear that the human development in the country relates to an influence of economic growth which is seen in per capita income (GDP per capita) which can be an indicator of welfare in the country..
\end{abstract}

Keywords: Human Development Index, Gross Domestic Product, Economic Growth, ASEAN Economic Community.

\section{INTRODUCTION}

The ASEAN Economic Community (AEC) will formally be implemented by the end of 2015 even though the process has begun since the signing of the ASEAN Framework Agreement on Economic Cooperation by ASEAN leaders in 1992 (Kemenko, [1]). Thus, true free trade has begun to be implemented gradually and progressively by ASEAN member countries through a Regional Trade Agreement (RTA) in the form of the ASEAN Free Trade Area (AFTA). In contrast to AFTA, ASEAN Economic Community (AEC) is more comprehensive in nature which includes four pillars with the aim of transforming ASEAN into a single market with an integrated production base, in a competitive economic zone, with increasingly equitable economic development and connected with global production networks. The ten ASEAN member countries include Indonesia, Malaysia, Singapore, Thailand, Brunei Darussalam, the Philippines, Laos, Vietnam, Myanmar, and Cambodia.

The implementation of ASEAN Economic Community is one of the strategic steps that can be taken by the Government of Indonesia in order to gain benefit as much as possible from economic globalization. Multilateral aspirations, especially those relating to regional economic integration, such as Asian Economic Community and others, in addition to providing wider market opportunities, also contain a number of complex challenges.

The economic growth of a country is determined by the increase of output measured by calculating the Gross Domestic Product (GDP) per capita. The progress of social and economic technology reflects as an indicator of the quality of life which determined by the economy of the people. Economic development refers to the improvement of the Human Development Index (HDI) indicator which is a composite index that covers three areas of human development which are basically considered. They are indicators namely (1) health sector: longevity; (2) education and knowledge; and (3) economic sector: decent living standards.

Human development means that development for humans and by humans. In this way, the main objective of the United Nations Development Program (UNDP) for the Human Development Report from the 1990s and to the present, is "highlighting the fact that development is in the first position and is fundamentally related to society". (Klugman J, [2]). All of these ideas are very well synthesized in the concept of human 
development introduced by economist Amartya Sen, a Nobel Prize winner for Economics, relates to the concept of his ability. Mahbub ul Haq and Pakistani economist have developed this concept and built it into the development of the Human Development Index (HDI). "Human development, he said, could be defined as the process of enlarging people's chosen capacity. The choices can be in various fields: political freedom and participation in people's lives, to be educated and have freedom of expression, survive and have a healthy life and enjoy standards of worthy lives" (Mahbub ul Haq, [3]).

The Human Development Index (HDI) is one indicator of a country's economic growth as indicated by the level of Gross Domestic Product (GDP) per capita. The study will measure how the relationship and influence of the Human Development Index (HDI) on economic growth (GDP) per capita in 10 (ten) members of ASEAN countries.

This research examines the relationships and influences between economic growth and human development, such as the following:

1) Ranis, G., Stewart, F., Ramirez, [4] explain that human development is considered as "the goal of human activity and economic growth, at the same time, is a strategic instrument in advancing it". So there is a dual relationship between causality and human development and economic growth. Economic growth makes it possible to achieve a high level of human development, on the one hand, an increase of the level human development leads to increase opportunities for economic growth. The causal relationship between economic growth and human development is stated in the following figure and human development will have a significant impact on development. Likewise, at the level where the increase in income also increases, various choices and capabilities are favorable at the same household level but also the government. In this way, growth will improve human development. Ranis and Steward [6], emphasize the importance of many empirical connections in both directions throughout time, from economic growth to human development, including investment reports.

3) Shome and Tondon [7], in their research, have investigated the movement of two GDP and HDI parameters and examined whether there is a significant correlation between their trends. The situation that higher levels of output directed to higher spending on education, health, and poverty reduction which will ultimately have an impact on population productivity leading to higher growth. That is, the higher the economic growth with increasing levels of output, the higher spending on HDI and poverty alleviation programs.

4) Various economists have studied the relationship between economic growth and increasing prosperity of a country, such as Sadequl Islam [8] who analyzed the relationship between GDP per capita and HDI in the developing countries. He observed the "inverse U" relationship of GDP per capita and the average HDI for developing countries.

5) Ciobanu Oana-Georgiana Neamțu Daniela-Mihaela [9], show that economic growth focuses exclusively on a single level to earn income. Human development implies the consolidation of all possibilities - whether economic, social, cultural or political, so that income means for human 1.

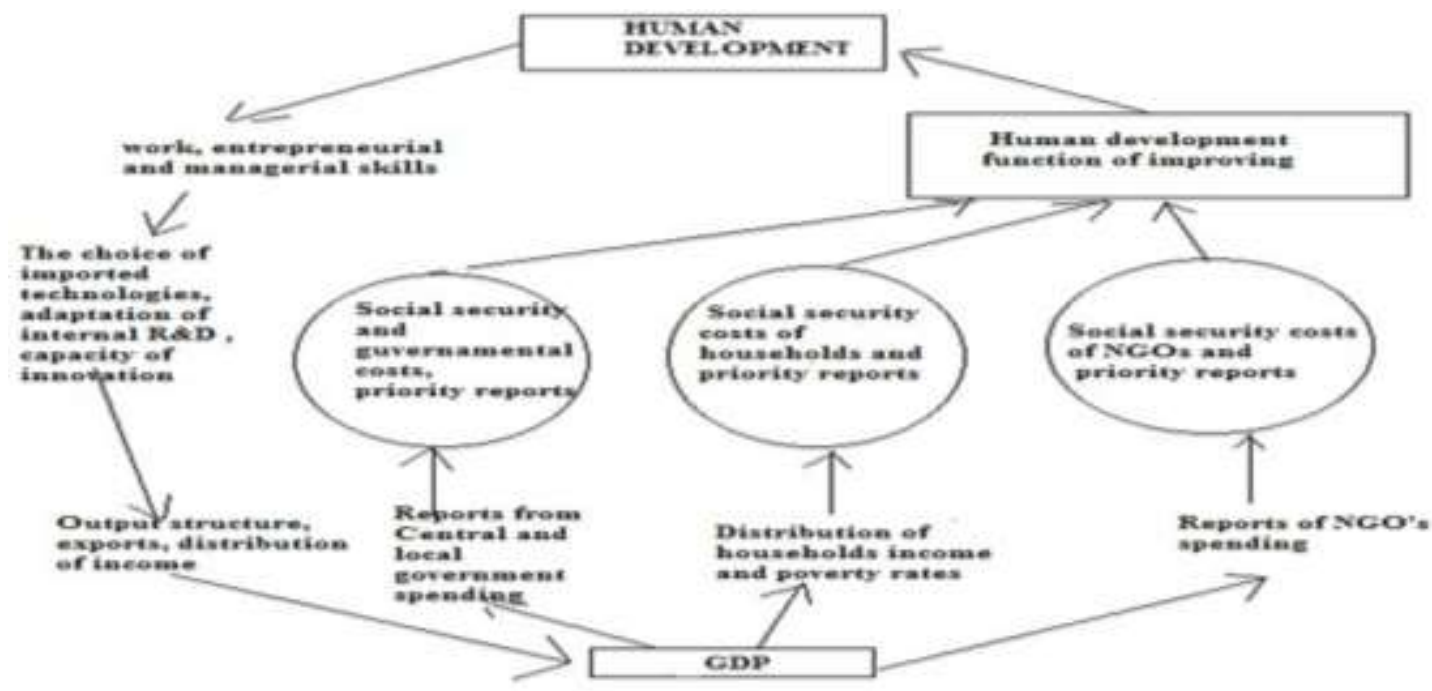

Figure 1. The Relationship Between Economic Growth And Human Development Source: Adaptation of Ranis, G., Stewart, f., Ramirez, [4], Economic Growth and Human Development, World Development, vol. 2, hal. 197-219.

2) Ranis [5], explains that capacity expansion and freedom lead to increased economic performance, development, but not the only one. Economic growth is a necessary but insufficient requirement for human 
development. No matter how much we try and how well we plan everything, education has been the most important social item. This mainly serves the community and is related to economic problems. Whatever is done in this case, education brings economic prosperity and cannot be done without considering important steps, namely social measures. If we go through this 'social' stage and focus directly on profit, success will be temporary because the basic foundation is not strong enough to absorb it. A strong economy based on a strong society, especially when talking about developing countries. The human development index is an innovative construction, which is largely arbitrary. This situation is very interesting and has proven to be very useful for disseminating information, analysis, and guidelines that are useful for public policy at global and national levels. This is an innovative construction which is the only relationship related to the past with the sending of ideas about human goodness.

6) Klodiana Gorica, Anita Gumeni [10], concluded that economic growth is a necessary but inadequate condition for achieving human development in a country. The critical role, in the development process, playing institutions that influence the design and implementation of policies and creating equal opportunities.

\section{RESEARCH METHODS}

Data analysis method uses causal analysis. This model includes and tests HDI which is thought to affect GDP per capita. Causal models usually use correlation analysis to determine correlation and influence. The data analysis method used in this study is a statistical analysis method that uses a linear regression equation through the Statistical Program for Social Science (SPSS) program.

The analysis of the causal model in this study uses a simple paradigm, where there are only two variables, such as figure 2 below:

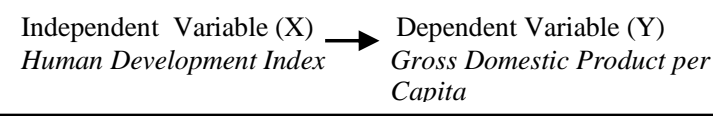
Capita

Figure 2. Research Model

The data used is a combination between the time series data. In this study, the time periods analyzed from 2000 to 2017 on PBD / GDP and HDI / HDI data objects from 10 (ten) ASEAN member countries. The secondary data implies from reports of international institutions such as the United Nations Development Program (UNDP), ASEAN Secretariat, and the World Bank.

\section{RESULTS AND DISCUSSION}

The following shows the HDI data and GDP per capita for the 10 (ten) ASEAN member countries as follows Table 1 .

\section{Brunei Darussalam}

Brunei Darussalam's GDP per capita has fluctuated from 2000 to 2017. The HDI value of Brunei Darussalam for 2017 is 0.853 - which places the country in a very high category of human development - positioning it in 39 of 189 countries and regions. Between 1990 and 2017, the value of HDI Brunei Darussalam increased from 0.782 to 0.853 , an increase of 9.1 percent.

\section{Cambodia}

After more than two decades of strong economic growth, Cambodia has achieved lower middle-income status with GDP per capita of US \$ 1,384 in 2017. Cambodia has maintained an average economic growth rate of $7.7 \%$ between 1995-2017, the economy sixth fastest in the world. When global demand increases in 2018 , economic growth is expected to reach 7\%, compared to $6.9 \%$ in 2017. Growth is expected to remain strong in the medium term.

Health and education remain important challenges and development priorities for Cambodia, where 32\% (or around 500,000) of children under five are stunting. While net enrollment in basic education increased from $82 \%$ in 1997 to $97 \%$ in 2016, a lower secondary settlement rate of 57\% in 2017 was far below the average for lower middle-income countries. In 2015, $70 \%$ of Cambodia's population (12.3 million people) did not have access to piped water, and 58\% (9.3 million people) did not have access to better sanitation.

Cambodia has made good strides in improving maternal health, early childhood development, and basic education in rural areas. The maternal mortality rate per 100,000 live births decreased from 472 in 2005 to 170 in 2014, and the under-five mortality rate decreased from 83 per 1,000 live births in 2005 to 35 per 1,000 in 2014.

\section{Indonesia}

The largest economy in Southeast Asia, Indonesia - a diverse archipelago with more than 300 ethnic groups has mapped impressive economic growth since overcoming the Asian financial crisis in the late 1990s. Indonesia's GDP per capita has continued to increase from $\$ 780$ in 2000 to $\$ 3,847$ in 2017 . Indonesia is the fourth largest country in the world, the world's 10th largest economy in terms of purchasing power varieties and members of G-20. Increasing human resources are an important agenda for Indonesia, in the quality of education in rural and remote areas. This program empowers community participation and adds benefits to improve teacher performance. This program has implemented in more than 200 schools and community satisfaction with teacher attendance has increased from 
$68 \%$ to $90 \%$, and teacher service performance from $55 \%$ to $91 \%$.
Between 2000 and 2017, Malaysian HDI value increased from 0.725 to 0.802 .

Table 1. Data on HDI and GDP per capita in 10 ASEAN countries in 2000 - 2017 (GDP per capita in USD)

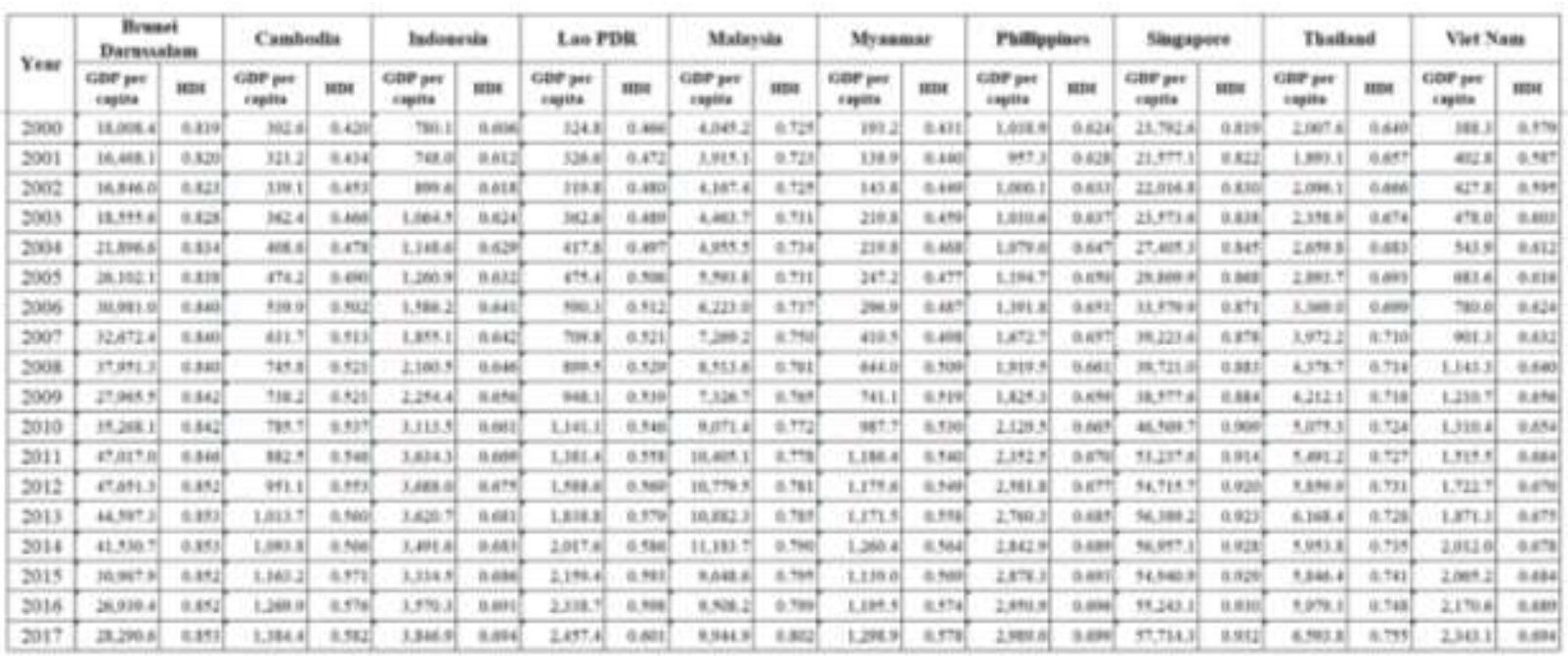

Source : Data from World Bank and UNDP

Indonesia's economic planning follows a 20-year development plan, from 2005 to 2025 . This segmented into a 5-year mid-term plan called the Medium-Term of Development Plan (each with a different development priority). The current medium-term of development plan - the third phase of the long-term plan runs from 2015 to 2020. It focuses on infrastructure development and social assistance programs related to education and healthcare. Millennium Development Goals: maternal health, child health, and universal education. Therefore, the efforts to improve the quality of human resources through an indicator of increasing Indonesia's HDI will increase with per capita income (GDP per capita).

\section{Lao PDR}

GDP growth per capita Lao PDR has averaged 7.8 percent over the past decade with per capita income reaching \$ 2,457 in 2017. Lao PDR has an investment program that aims to reduce the prevalence of malnutrition, improving the quality of primary and preprimary education, guarding girls in schools, increasing access and quality of health services, reducing vulnerability and inclusive access to social services.

\section{Malaysia}

Malaysia's GDP growth per capita has fallen in the last 3 years (2015-20017) over the past decade, with per capita income reaching $\$ 2,457$ in 2017 . The HDI value of Malaysia for 2017 is 0.802 which places the country in a very high category of human development positioning it in 57 of 189 countries and regions.

\section{Myanmar}

Myanmar is a lower middle-income economy with a GDP per capita of $\$ 1,298$ in 2017. If seen from the development of GDP growth per capita from 2000 2017 it has a fairly stable growth increase. Myanmar's HDI value for 2017 is 0.578 - which places the country in the medium human development category positioning it in 148 of 189 countries and regions. Between 2000 and 2017, Myanmar's HDI value increased from 0.431 to 0.578 .

\section{Philippines}

Philippines per capita GDP tends to increase every year. Philippines per capita GDP increased since 2000, although it dropped in 2001, only experienced one time in the 18-year decade until 2017. The Philippines HDI value for 2017 is 0.699 - which puts this country in the medium human development category - positioning it at 113 from 189 countries and regions.

\section{Singapore}

Singapore is a high-income economy with a GDP per capita of US \$ 57,714 per 2017. GDP per capita increases every year from 2000 to 2017.

The value of Singapore's HDI for 2017 is 0.932 which places the country in a very high category of human development - positioning it in 9 of 189 countries and regions. Between 2000 and 2017, the value of Singapore's HDI increased from 0.819 to 0.932 .

\section{Thailand}

Over the past four decades, Thailand made remarkable progress in social and economic development, moved 
from low-income countries to high-income countries in less than a generation. After average growth slowed to $3.5 \%$ during 2005-2015, with a decline to $2.3 \%$ in 20142016, Thailand's GDP per capita tended to be stable, although there has been a decline slightly over the past 5 years until 2017 Thailand's GDP per capita reached \$ 6,593 .

Results of Correlation and Effect of the Human Development Index (HDI) on Economic Growth (GDP) per capita

Based on the data of economic growth rates in 10 (ten) ASEAN member countries, the results of the study explained the process as the following criteria:

1. The strong and positive correlation

Table 2. Range and Degree of Correlation Coefficients

\begin{tabular}{|c|c|}
\hline Range of Correlation Coefficients & Degree of Correlation \\
\hline $0,80-1,00$ & very strong positive \\
\hline $0,60-0,79$ & strong positve \\
\hline $0,40-0,59$ & moderate positive \\
\hline $0,20-0,39$ & weak positive \\
\hline $0,00-0,19$ & very weak postive \\
\hline$(-0,20)-(-0,39)$ & weak negative \\
\hline$(-0,40)-(-0,59)$ & moderate negative \\
\hline$(-0,60)-(-0,79)$ & strong negative \\
\hline$(-0,80)-(-1,00)$ & very strong negative \\
\hline
\end{tabular}

2. The value of significant hypotheses test is significant $<0,05$ and $t$ count $>\mathrm{t}$ table.
2. Cambodia

Based on table 3 above, the correlation between HDI and GDP per capita of Cambodia is 0.957 which means that the correlation is very strong positively, and the effect of HDI on GDP per capita is significant with $\alpha=0.000$.

3. Indonesia

Based on table 3 above, the correlation between HDI and GDP per capita in Indonesia is 0.969 which means that the correlation is very strong positively, and the effect of HDI on GDP per capita is significant with $\alpha=0.000$.

4. Lao PDR

Based on table 3 above, the correlation between HDI and GDP per Lao PDR of 0.974 means that the correlation is very strongly positive, and the effect of HDI on GDP per capita is significant with $\alpha=$ 0.000 .

5. Malaysia

Based on table 3 above, the correlation between HDI and GDP per capita in Malaysia is 0.810 which means that the correlation is very strong positively, and the effect of HDI on GDP per capita is significant with $\alpha=0.001$.

6. Myanmar

Based on table 3 above, the correlation between HDI and Myanmar's GDP per capita is 0.810 meaning that the correlation is very strong positively, and the effect of HDI on GDP per capita is significant with $\alpha=0.000$.

Table 3. HDI Correlation and Significance to GDP per capita In 10 ASEAN Countries 2000-2017

\begin{tabular}{|c|c|c|c|c|c|c|c|c|c|c|}
\hline Correlatios & Brunei & Cambodia & Indonesia & Lao PDR & Malaysia & Myanmar & Pbillppines & Singapore & Thailand & Vietnam \\
\hline $\mathbf{r}$ & 0.769 & 0.957 & 0.969 & 0.971 & 0.810 & 0.965 & 0.974 & 0.981 & 0.967 & 0.977 \\
\hline$r^{2}$ & 0.591 & 0.916 & 0.940 & 0.949 & 0.655 & 0.931 & 0.948 & 0.969 & 0.934 & 0.955 \\
\hline \multicolumn{11}{|c|}{ Hypothesis tests : Significance Level } \\
\hline$\alpha<0.05$ & 0.000 & 0.000 & 0.000 & 0.000 & 0.001 & 0.000 & 0.000 & 0.000 & 0.000 & 0.000 \\
\hline Lopothesss : : & & & & & & & & & & \\
\hline $\begin{array}{r}\mid \text { lest }=1 \text { lable } \\
\text { (t table }-2.12)\end{array}$ & 4.805 & 13.232 & 15.780 & 17.310 & 4.360 & 14.747 & 17.113 & 22.422 & 15.094 & 18.400 \\
\hline Conclusion & \multicolumn{10}{|c|}{ Correlation Significance Between HDI and GDP per capita in ASEAN 10 Countries } \\
\hline
\end{tabular}

From the results of processing correlation data and significant effects in table 3 , the following levels of correlation and significance effects generated table 3.:

From the data in table 3 above, the following interpretations explained:

1. Brunei Darussalam

Based on table 3 above, the correlation between HDI and GDP per capita of Brunei Darussalam is 0.769 which means that the correlation is quite positive, and the effect of HDI on GDP per capita is significant with $\alpha=0.000$.
7. Philippines

Based on table 3 above, the correlation between HDI and GDP per capita in the Philippines is 0.974 meaning that the correlation is very strong positively, and the effect of HDI on GDP per capita is significant with $\alpha=0.000$.

8. Singapore

Based on table 3 above, the correlation between HDI and GDP per Singapore capita is 0.984 , which means that the correlation is very strong positively, and the effect of HDI on GDP per capita is significant with $\alpha=0.000$. 
9. Thailand

Based on table 3 above, the correlation between HDI and GDP per capita of Thailand is 0.967 which means that the correlation is very strong positively, and the effect of HDI on GDP per capita is significant with $\alpha=0.000$.

10. Vietnam

Based on table 3 above, the correlation between HDI and GDP per capita of Vietnam is 0.977 which means that the correlation is very strong positively, and the effect of HDI on GDP per capita is significant with $\alpha=0.000$.

\section{CONCLUSION}

Economic growth is an important factor in the economic success of a country so that every country always tries to increase its economic growth. The level of human development in a country indicates the value of the Human Development Index (HDI), while the growth rate of country indicated the Gross Domestic Product (GDP) per capita. It is known that the ASEAN Economic Community emerged in 2015. Of course, it is an opportunity and a challenge for each country in the management of human resources and science and technology. Every ASEAN member country has a level of economic growth and quality of human resources that is a source of state power.

Economic growth makes this possible to achieve a high level of human development and on the other hand, an increase in the level of human development leads to increase opportunities for economic growth. The causal relationship between economic growth and human development becomes a relationship that affects each other. So it is concluded that human development in a country relates to and affects economic growth which shows in per capita income (GDP per capita).

Based on the results of processing GDP data per capita and HDI in 10 (ten) ASEAN member countries (Indonesia, Singapore, Malaysia, Thailand, Brunei Darussalam, Philippines, Laos, Vietnam, Myanmar, and Cambodia) in 2000 - 2017. The expected results there is a positive and direct correlation between HDI and GDP per capita, the HDI variable has a significant effect on GDP per capita of a country.

From the results of the study, the relationship and influence of HDI and GDP per capita in 10 (ten) ASEAN member countries namely Indonesia, Singapore, Malaysia, Thailand, Brunei Darussalam, the Philippines, Laos, Vietnam, Myanmar, and Cambodia were significant and had a significant effect. So, this study justifies studies such as Anas et. Al [11], Ciobanu Oana [9], Swaha Shome, Sarika Tondon [7], Mihuţ Ioana Sorina [12], Munyemana E. [13], Akbar Khodabakhshi [14] shows that there are a correlation and influence of HDI on the level of economic growth of a country as shown in the GDP per capita indicator.
For further research, researchers can add variables and indicators that prove what aspects have a correlation and influence on GDP. Therefore, further research involving indicators and variables that affect GDP as research conducted by Ranis et al. [4], Mihut Ioana Sorina [12], and other related research studies will be modified.

Researchers must also see that each country must also know their SWOT (Strength, Weakness, Opportunity, and Threat) in several sectors such as Finance, Monetary, Investment, Infrastructure, Food, and Energy, or see each level of 12 pillars in the Competitiveness Index Global.

\section{REFERENCES}

[1] Kemenko, Laporan Keuangan Tahun 2015 (Audited), 2015, https://www.ekon.go.id/ publikasi/view/laporan-keuangan-tahunan.2125. html.

[2] Klugman J. - lead author. Human Development Report 2010- The Real Health of Nations: Pathways to Human Development. Published for the UNDP. 2000.

[3] Haq, Mahbub ul. 1995. Reflections on Human Development, New York, Oxford University Press

[4] Ranis. G.. Stewart. F.\& Ramirez. A. (2000). Economic growth and human development. QEH Working Paper \# 18.

[5] Ranis Gustav. 2004. Human Development and Economic Growth. Yale University. Center Discussion Paper No.887.

[6] Ranis. G.. Stewart F.. 2005. Dynamic Links between the Economy and Human Development. United Nations. Department of Economics and Social Affairs. Working Papers. No.8.

[7] Swaha Shome. Sarika Tondon. 2010. Balancing Human Development With Economic Growth: A Study of Asean 5. Annals of the University of Petroşani. Economics. 10 (1). p.335-348.

[8] Sadequl Islam, 1995. "The human development index and per capita GDP," Applied Economics Letters, Taylor \& Francis Journals, vol. 2(5), pages 166-167.

[9] Ciobanu Oana-Georgiana Neamțu DanielaMihaela. 2015. Correlations Between Human Development and Economic Growth. Annals of the "Constantin Brâncuşi” University of Târgu Jiu. Economy Series. Issue 1. volume I/2015. p.121.

[10] Klodiana Gorica. Anita Gumeni. 2013. Towards Sustainable Development. Relationship Between HDI And GDP per Capita in Albania. International Journal Of Scientific \& Engineering Research. Volume 4. Issue 12. December-2013. 776 ISSN 2229-5518. 
[11] Anas Ibrahim Kubalu. Aminu Muhammad Mustapha. Zainab Said Suwaid. 2017. A Dynamic Analysis of the Relationship between Human Development and Economic Growth in Nigeria. International Journal of Advanced Studies in Economics and Public-Sector Management

[12] Mihuţ Ioana Sorina. 2013. Economic Growth And The Convergence Criteria Within Emerging Economies Of Central And Eastern Europe. Doctoral Thesis. Cluj-Napoca. p.19.

[13] Munyemana E. 2013. Assessing the relationship between Economic Growth and HDI in Rwanda. IPAR 3rd Annual Research Conference.

[14] Akbar Khodabakhshi. Relationship between GDP and Human Development Indices in India. 2011. International Journal of Trade. Economics and Finance. Vol. 2. No. 3. June 2011. 